\title{
Denitrogenization Mechanism from Molten Steel by Flux Treatment
}

\author{
Ryoichi YAMANAKA, Kanehiro OGAWA, Hideki IRITANI') and Shinji KOYAMA
}

Iron and Steel Research Laboratories, Kobe Steel, Ltd., Wakinohama-cho, Chuo-ku, Kobe, Hyogo-ken, 651 Japan.

1) Kakogawa Works, Kobe Steel, Ltd., Kanazawa-cho, Kakogawa, Hyogo-ken, 675-01 Japan.

(Received on June 17, 1991; accepted in final form on September 20,1991)

\begin{abstract}
Experiments of nitrogen desorption from molten steel by flux treatment have been proceeding and the reaction rates have been investigated. The flux of the $\mathrm{CaO}-\mathrm{Al}_{2} \mathrm{O}_{3}-\mathrm{CaF}_{2}-\mathrm{BaF}_{2}-\mathrm{SiO}_{2}-\mathrm{MgO}$ system is effective for nitrogen desorption from molten steel. The nitrogen transfer rate from the steel to the gas phase could be increased by using the present flux, when the free surface of molten steel is exposed to argon atmosphere. The reason for the increase is that surface activity elements such as oxygen and sulphur in the molten steel were decreased and the interfacial resistance between the metal and gas was reduced. Under the present conditions, the nitrogen desorption from molten steel to the gas phase was more rapid than the nitrogen absorption of slag from the molten steel. The rate determination step of nitrogen desorption from molten steel is changed from the interfacial chemical reaction step to the mass transfer of the metal phase, depending on the reduction of oxygen and sulphur in metal.
\end{abstract}

KEY WORDS: ladle refining; slag-metal reaction; denitrogenization; flux.

\section{Introduction}

For steel products like deep drawn sheets and line pipes, it is necessary to remove nitrogen from the steel as much as possible. A degassing process of molten steel is applied to reduce nitrogen in the metal. However, by only using the degassing process, it is difficult to achieve the desired level of nitrogen concentration. Therefore, it is necessary to develop other treatments to decrease nitrogen in molten steel. In spite of many efforts by researchers, an efficient method of nitrogen removal from molten steel has not been put into operation at a plant.

There have been several reports of nitrogen removal from molten steel by flux. ${ }^{1-4)}$ It is possible to apply the refining of slag for denitrogenization to operations at plants easily. Suito and Inoue ${ }^{1)}$ have reported that the feasibility of denitrogenization by slag was estimated by measuring the nitrogen distribution between liquid iron and various slags. Their results found that the nitrogen concentration can be lowered to 20 from $40 \mathrm{ppm}$ at a $0.05 \% \mathrm{Al}$ content using the $\mathrm{BaO}-\mathrm{SiO}_{2}-\mathrm{Al}_{2} \mathrm{O}_{3}$ slag, and the use of the $\mathrm{BaO}-\mathrm{TiO}_{2}-\mathrm{Al}_{2} \mathrm{O}_{3}$ slag with only $2 \mathrm{~kg} /$ steel-ton makes the metal decrease its nitrogen content to $16 \mathrm{ppm}$.

In the present study, experiments of nitrogen desorption from molten steel by flux were carried out and analyzed on the basis of reaction rates. The feasibility of using denitrogenization by flux at a plant was investigated.

\section{Experimental Method}

The experimental apparatus is shown schematically in
Fig. 1. A magnesia crucible was charged with electrolytic iron, graphite, and iron sulphide. The crucible was placed in a graphite container and kept at an experimental temperature of 1823-1923 K, under Ar atmosphere inside an induction furnace. During an experiment, argon gas was blown through an alumina tube (ID. $4 \mathrm{~mm}$ ) at a height of $50 \mathrm{~mm}$ from the free surface of the molten steel. The gas flow rate was $0.01 \mathrm{~m}^{3} / \mathrm{min}$. After melting, electrolytic manganese, manganese nitride, aluminum, and ferrosilicon were added to adjust the contents as shown in Table 1.

The flux compositions for the present study are given in Table 2. The present systems were based on the system of $\mathrm{CaO}-\mathrm{Al}_{2} \mathrm{O}_{3}-\mathrm{CaF}_{2}$, one of the conventional slag contents of secondary refining. Suito and Inoue ${ }^{1)}$ have proposed the systems of $\mathrm{BaO}-\mathrm{SiO}_{2}-\mathrm{Al}_{2} \mathrm{O}_{3}$ and $\mathrm{BaO}-$ $\mathrm{TiO}_{2}-\mathrm{Al}_{2} \mathrm{O}_{3}$. Barium in a slag is possibly effective for nitrogen removal. However, $\mathrm{BaO}$ makes the melting

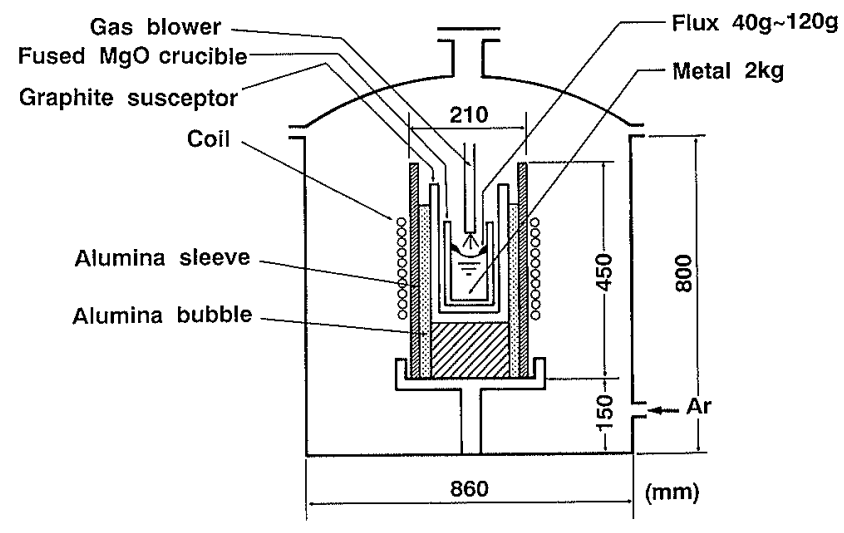

Fig. 1. Experimental apparatus. 
Table 1. Composition of molten steel. (wt $\%$ )

\begin{tabular}{ccccccc}
\hline $\mathrm{C}$ & $\mathrm{Si}$ & $\mathrm{Mn}$ & $\mathrm{P}$ & $\mathrm{S}$ & $\mathrm{Al}$ & $\mathrm{N}$ \\
\hline 0.05 & 0.15 & 0.20 & $\mathrm{Tr}$ & $0.001-0.03$ & $\mathrm{Tr}$ & 0.005
\end{tabular}

Table 2. Composition of flux. (wt $\%$ )

\begin{tabular}{lcccccc}
\hline & $\mathrm{CaO}$ & $\mathrm{Al}_{2} \mathrm{O}_{3}$ & $\mathrm{SiO}_{2}$ & $\mathrm{MgO}$ & $\mathrm{CaF}_{2}$ & $\mathrm{BaF}_{2}$ \\
\hline Flux (a) & 55 & 13 & 10 & 10 & 12 & 0 \\
Flux (b) & 55 & 13 & 10 & 10 & 6 & 6 \\
Flux (c) & 55 & 13 & 10 & 10 & 0 & 12 \\
\hline
\end{tabular}

temperature of slag rise up, and makes the slag condition change. Hence, in the present study, barium fluoride was selected instead of barium oxide. It was decided to keep the sum of $\mathrm{BaF}_{2}$ and $\mathrm{CaF}_{2}$ contents equal to $12 \%$ in order to be similar content of fluoride to the conventional slag.

The operational slags unavoidably contained silica and magnesia, and these were mixed into the present flux in order to have the same conditions. Flux was blended in a mortar and placed on the molten steel.

Metal and slag were sampled at certain intervals after the flux melted. Metal samples were taken by suction into a silica tube and then the samples were cooled in water. The slags were sampled using two methods, in which suction into an alumina tube and dipping with an iron rod were used. The choice of methods depended on the slag fluidity. Damage to the alumina tube was not observed upon slag sampling.

\section{Experimental Results}

The experimental results using $120 \mathrm{~g}$ of flux (c) (see Table 2) is shown in Fig. 2. Under these experimental conditions, all of the surface of the molten steel was covered with slag. Time measurement was started at the melting of the flux. The nitrogen concentration of the metal was decreasing with time so as to be in equilibrium. After an hour of treatment, the concentration was close to a state of balance. Hence, the values after $1 \mathrm{~h}$ were regarded as the nitrogen distribution ratio. However, the experimental values may differ from the equilibrium values.

Figure 3 shows the comparison of the nitrogen distribution ratio between flux (a) and (c) (see Table 2), when using $120 \mathrm{~g}$ of the flux. The distribution ratio of flux (c) was 3 and twice greater than flux (a). The nitrogen distribution of the slag is high when using the flux with $\mathrm{BaF}_{2}$ and the maximum in the present study is 3 .

The effect of flux consumption on nitrogen change is shown in Fig. 4 for flux (c). Nitrogen concentration in molten steel was decreasing with time. In the same time period, the nitrogen reduction with $40 \mathrm{~g}$ of flux was larger than with $120 \mathrm{~g}$.

In order to compare the reaction rates of the fluxes, the nitrogen desorption ratio was decided as follows.

Nitrogen desorption ratio $=[\% \mathrm{~N}]_{30} /[\% \mathrm{~N}]_{0} \times 100(\%)$

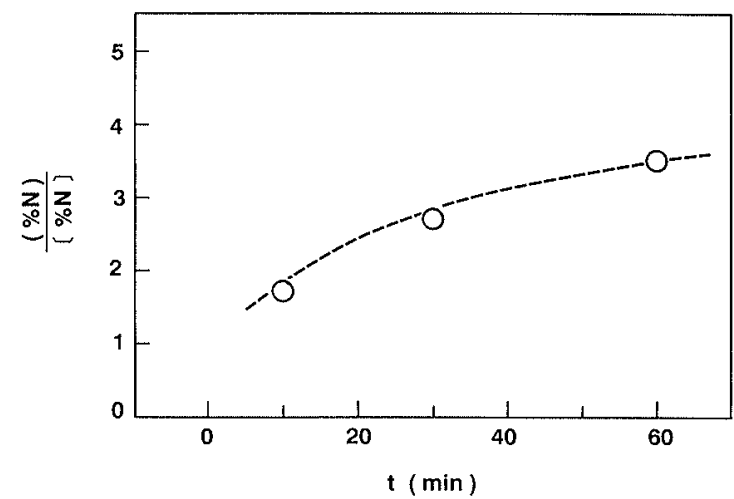

Fig. 2. Nitrogen distribution ratio with flux of the system $\mathrm{CaO}-\mathrm{Al}_{2} \mathrm{O}_{3}-\mathrm{SiO}_{2}-\mathrm{CaF}_{2}-\mathrm{BaF}_{2}-\mathrm{MgO}$.

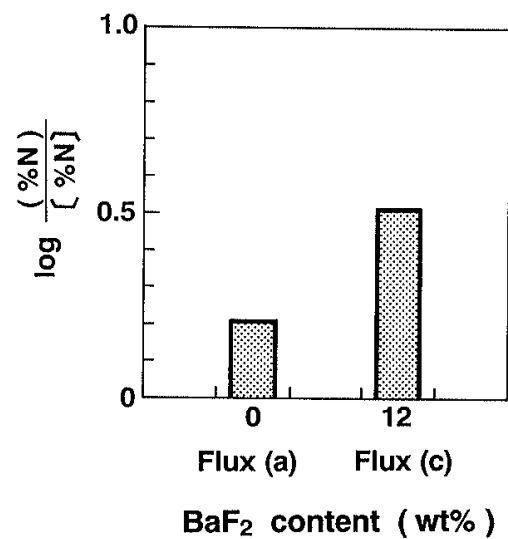

Fig. 3. Effect of $\mathrm{BaF}_{2}$ content on nitrogen distribution ratio.

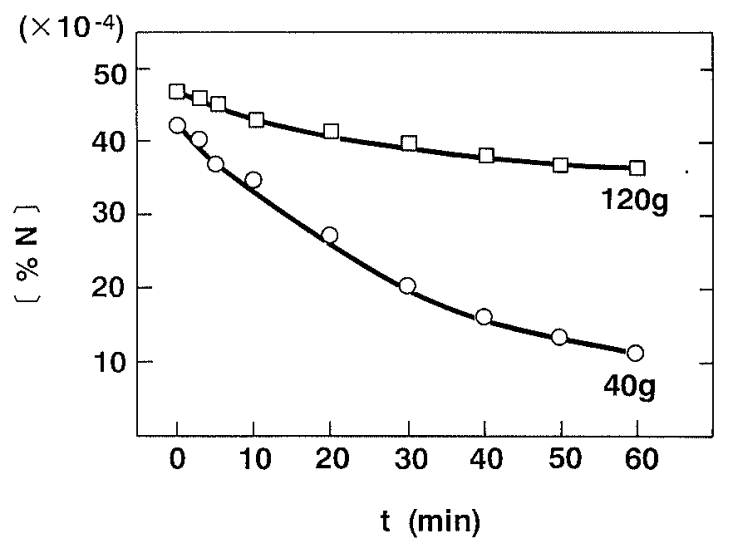

Fig. 4. Relation between nitrogen content in metal and time.

where, $[\% \mathrm{~N}]_{30}$ : nitrogen concentration at $30 \mathrm{~min}$

$[\% \mathrm{~N}]_{0}$ : initial nitrogen concentration in molten steel.

The influence of flux weight and composition on nitrogen desorption ratio is shown in Fig. 5. With $120 \mathrm{~g}$ of the flux, the surface of the molten steel was isolated from Ar atmosphere by the slag. When the flux weight was less than $120 \mathrm{~g}$, the surface was exposed to argon gas directly, and nitrogen in the metal could desorb the metal to the gas phase. Figure 6 shows the mass balance of nitrogen between slag and metal after each experiment. For 40 and $80 \mathrm{~g}$ of flux, nitrogen desorption from steel to slag was no more than $10 \%$ of the decrease in nitrogen in the metal, the other $90 \%$ was released to the gas phase. 


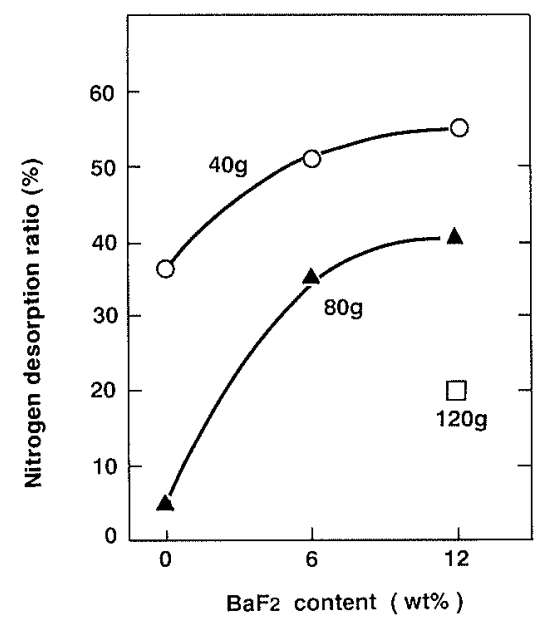

Fig. 5. Influence of flux weight on nitrogen desorption ratio

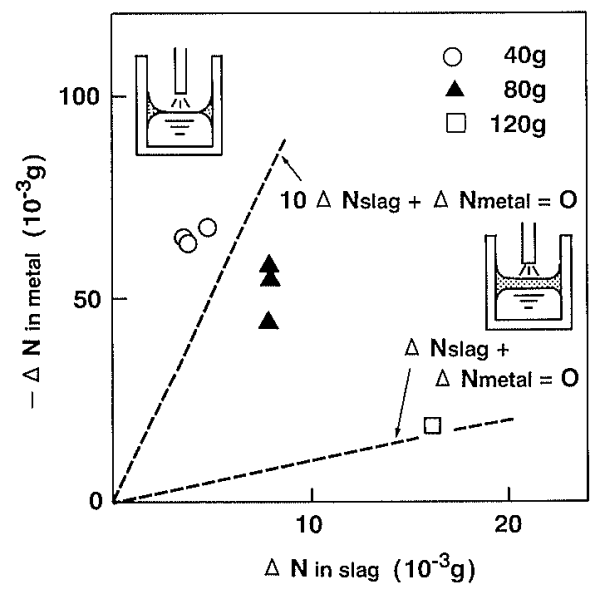

Fig. 6. Mass balance of nitrogen between slag and metal.

The nitrogen transfer to the gas phase was more rapid than to the slag phase, and the transfer controlled the denitrogenization from molten steel using the 40 and $80 \mathrm{~g}$ of flux.

The transportation rate from molten steel to the gas phase is usually determined by the free surface area under the same conditions. The free surface area of the molten steel was determined by flux weight; all of the surface of the steel was covered by the slag with $120 \mathrm{~g}$ of the flux, when the flux weight was $40 \mathrm{~g}$, most of the surface was exposed to argon gas. The flux composition should not have been related to the free surface area. However, as shown in Fig. 5, the difference in the nitrogen desorption ratio arose from the change in the flux composition. The results indicate that the flux with $\mathrm{BaF}_{2}$ has influenced not only the absorption of slag, but also the nitrogen transfer to gas phase.

The components in steel, oxygen, and sulphur were changed using $40 \mathrm{~g}$ of the present flux as shown in Fig. 7. The reduction of oxygen and sulphur was compared with the $\mathrm{BaF}_{2}$ concentration using $40 \mathrm{~g}$ of the flux, as shown in Fig. 8. $\underline{O}$ and $\underline{S}$ were averaged during experimentation without radical reduction at the beginning. The nitrogen desorption ratios are also shown in Fig. 8. Oxygen and sulphur were decreasing and the desorption rate was increasing with rising $\mathrm{BaF}_{2}$

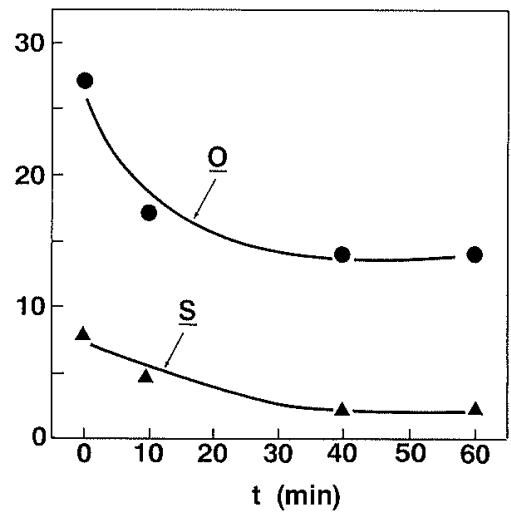

Fig. 7. Relation between oxygen and sulphur contents and time.

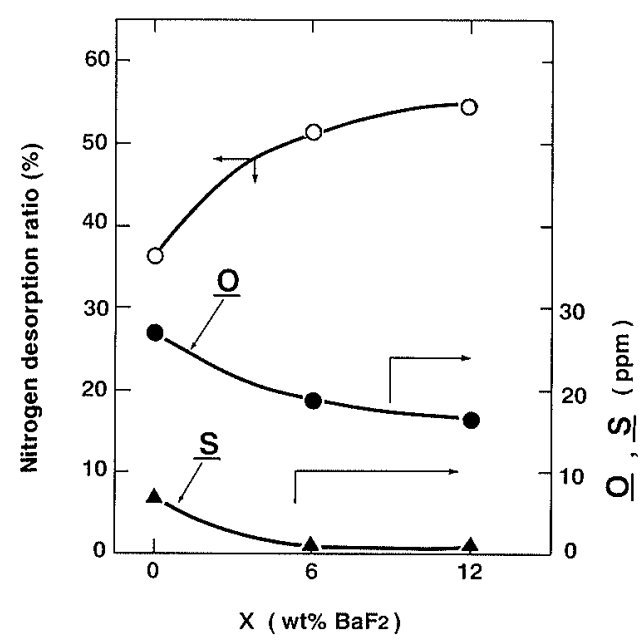

Fig. 8. Influence of $\mathrm{BaF}_{2}$ content in flux on nitrogen desorption ratio and content of oxygen and sulphur in metal.

concentration; the reduction of oxygen and sulphur in molten steel promoted the nitrogen desorption from the steel.

Oxygen and sulphur in molten steel are recognized surface active elements, the elements concentrate at the surface of the liquid and behave as interfacial resistance between the metal and gas phase. The barium fluoride in the system of $\mathrm{CaO}-\mathrm{Al}_{2} \mathrm{O}_{3}-\mathrm{CaF}_{2}-\mathrm{BaF}_{2}$ made the slag basicity rise up. As oxygen and sulphur in molten steel were reduced by the flux, the interfacial resistance decreased and the nitrogen desorption rate from the metal to gas phase was accelerated.

\section{Discussion}

\subsection{Determination of the Overall Reaction Rate Con- stant}

The rate constant of nitrogen desorption from molten steel could be calculated from the experimental data.

When the nitrogen reaction rate was controlled by the transfer from molten steel to gas, the overall reaction rate was represented by a first order equation, the equation was assumed to be Eq. (1).

$$
-\frac{d[\% \mathrm{~N}]}{d t}=K o v \frac{A}{V}\left\{[\% \mathrm{~N}]-K \sqrt{P_{\mathrm{N}_{2}}}\right\}
$$




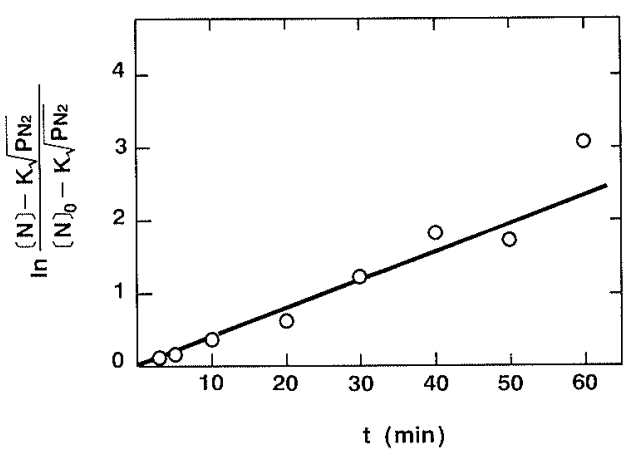

Fig. 9. Relationship between time and $\ln \left\{\left([\mathrm{N}]-k \sqrt{P_{\mathrm{N}_{2}}}\right)\right\}$ $\left([\mathrm{N}]_{0}-k \sqrt{P_{\mathrm{N}_{2}}}\right)$.

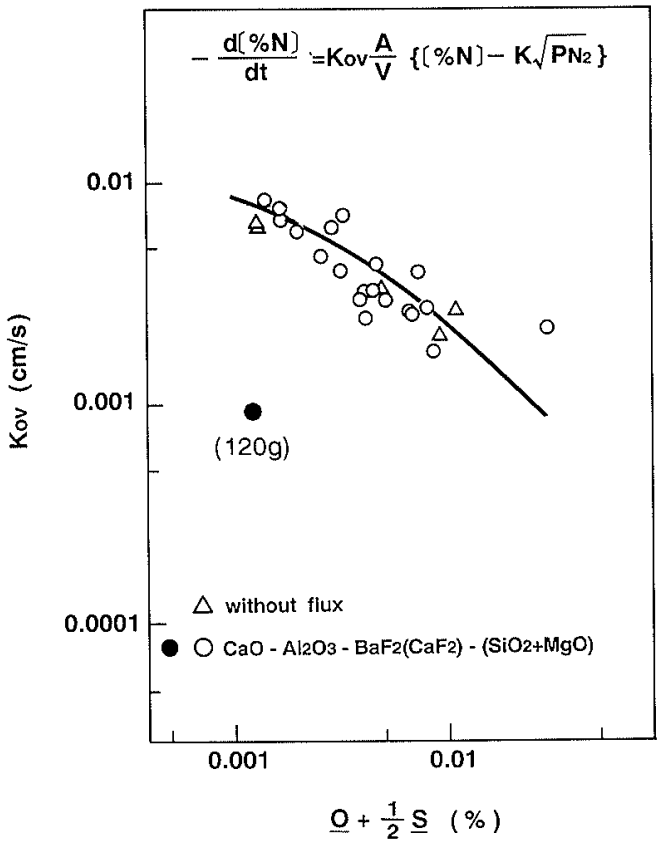

Fig. 10. Overall reaction rate constant plotted against $\underline{O} \pm \underline{S} / 2$.

Integration of Eq. (1) gives

$$
\ln \frac{\left([\% \mathrm{~N}]-K \sqrt{P_{\mathrm{N}_{2}}}\right)}{\left([\% \mathrm{~N}]_{0}-K \sqrt{P_{\mathrm{N}_{2}}}\right)}=K o v \frac{A}{V} t
$$

where, $A$ : interfacial area

(The interfacial area is defined as the surface area of molten steel which is not covered with flux.)

$K$ : equilibrium constant, $\mathrm{N}_{2}=2 \mathrm{~N}$

$[\% \mathrm{~N}]$ : nitrogen concentration in the molten steel at time $t$

$[\% \mathrm{~N}]_{0}$ : initial nitrogen concentration in the molten steel

$P_{\mathrm{N}_{2}}$ : nitrogen partial pressure

$V$ : volume of the molten steel.

The relationship between time and the left hand of Eq. (2) for $40 \mathrm{~g}$ of flux (c), for example, is shown in Fig. 9. The relationship was nearly represented by a first order equation; the assumption of Eq. (1) was confirmed.

Generally, the effect of oxygen and sulphur on denitrogenization is represented by $\underline{\mathrm{O}}+\mathrm{S} / 2 .{ }^{5}$ ) Therefore, the overall reaction rate constants were plotted against $\mathrm{O}+\mathrm{S} / 2$ as shown in Fig. 10. Open circles were obtained

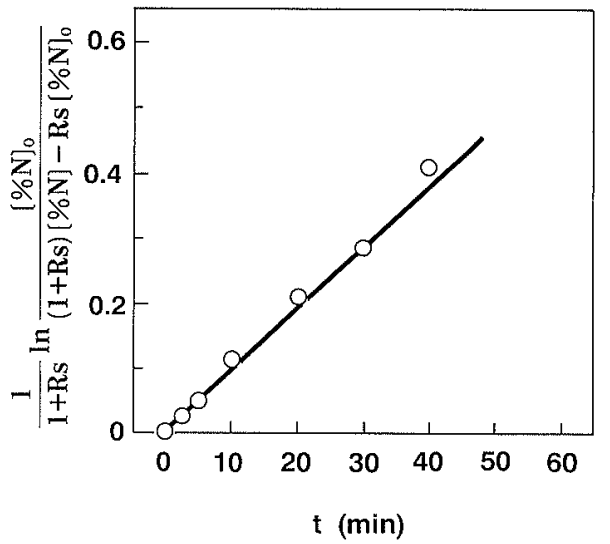

Fig. 11. Relationship between time and $\frac{1}{1+R s} \ln \left\{\frac{[\% \mathrm{~N}]_{0}}{(\mathrm{I}+R s)[\% \mathrm{~N}]-R s\{\% \mathrm{~N}]_{0}}\right\}$

from Eq. (2). Kov was increasing with the reduction of oxygen and/or sulphur in molten steel. As mentioned before, the $\underline{O}$ and $\underline{S}$ were averaged during the experiment.

By using $120 \mathrm{~g}$ of flux, the oxygen and sulphur also changed. For the comparison of the overall reaction rate between transfer to gas phase and to slag phase, the Kov was obtained from the following equations when the flux weight was $120 \mathrm{~g}$.

$$
\begin{aligned}
- & \frac{d[\% \mathrm{~N}]}{d t}=K o v \frac{A}{V}\left\{[\% \mathrm{~N}]-\frac{(\% \mathrm{~N})}{L_{N}}\right\} \\
= & K o v \frac{A}{V}\left\{\left(1+\frac{W_{M}}{L_{N} W_{S}}\right)[\% \mathrm{~N}]-\frac{W_{M}}{L_{M} W_{S}}[\% \mathrm{~N}]_{0}\right\} \\
& \frac{1}{1+R s} \ln \left\{\frac{[\% \mathrm{~N}]_{0}}{(1+R s)[\% \mathrm{~N}]-R s[\% \mathrm{~N}]_{0}}\right\}=K o v \frac{A}{V} t
\end{aligned}
$$

here, $\quad R s=W_{M} / L_{N} W_{S}$

$L_{N}:$ nitrogen distribution between metal and slag

$W_{M}$ : weight of metal

$W_{S}$ : weight of slag.

As shown in Fig. 11, the linearity between time and the left hand of Eq. (4) was confirmed.

The solid circle in Fig. 10 was obtained from Eq. (4), and the $K o \dot{v}$ of the $120 \mathrm{~g}$ of flux was lower than the Kov of other slags. Thus, even if the oxygen and/or sulphur concentrations were the same, the nitrogen desorption from molten steel to the gas phase was faster than the nitrogen absorption to the slag.

Sasagawa et al. ${ }^{6}$ have investigated removal of nitrogen from molten steel by using flux with barium oxide. The overall rate constant obtained from the result using of the $\mathrm{BaO}-\mathrm{SiO}_{2}-\mathrm{Al}_{2} \mathrm{O}_{3}$ slag was $0.0039 \mathrm{~cm} / \mathrm{sec}$. The value obtained in the present study was $0.001 \mathrm{~cm} / \mathrm{sec}$, and was smaller than the value reported by Sasagawa et al. In their experiment, the liquid steel was obtained by induction melting, and was stirred strongly. However, in the present study, the steel was melted using the graphite container (see Fig. 1) heated by the induction, and was not stirred so much. The difference between the literature 
and the present result depended on the stirring strength of the molten steel.

\subsection{Reaction Steps}

Nitrogen desorption from molten steel to the gas phase could be separated into three reaction steps:

Step 1. liquid phase transfer, nitrogen transfer from bulk liquid to interface.

Step 2. chemical reaction at interface, $2 \mathrm{~N} \rightarrow \mathrm{N}_{2}$.

Step 3. gas phase transfer, nitrogen transfer from interface to bulk gas.

The reaction rates of the above steps were represented by the following equations.

$$
\begin{aligned}
& -\frac{d[\% \mathrm{~N}]}{d t}=K m \frac{A}{V}\left\{[\% \mathrm{~N}]-[\% \mathrm{~N}]_{i}\right\} \ldots \ldots \ldots \ldots . . . . . \\
& -\frac{d[\% \mathrm{~N}]}{d t}=K c \frac{A}{V}\left\{[\% \mathrm{~N}]_{i}^{2}-k^{2}\left(P_{\mathrm{N}_{2}}\right)_{i}\right\} \ldots \ldots \ldots \ldots . \\
& -\frac{d[\% \mathrm{~N}]}{d t}=K g \frac{100 M_{\mathrm{N}_{2}} A}{R T \rho V}\left\{[\% \mathrm{~N}]_{i}^{2}-k^{2}\left(P_{\mathrm{N}_{2}}\right)_{i}\right\}
\end{aligned}
$$

where, $M_{\mathrm{N}_{2}}$ : molecular mass of nitrogen

$[\% \mathrm{~N}]_{i}$ : nitrogen concentration at interface of molten steel

$\left(P_{\mathrm{N}_{2}}\right)_{i}$ : nitrogen partial pressure at interface of gas phase

$\rho:$ density of the melt.

The overall rate constant could be described on the basis of a mixed control model of steps (1)-(3), as follows.

$$
\begin{aligned}
& \frac{1}{K o v}=\frac{1}{K m} \\
& +\frac{1}{K c\left([\%]_{i}+k P_{N}\right)}+\frac{\rho}{100 M_{\mathrm{N}_{2}}}+\frac{R T K^{2}}{K g\left([\%]_{i}+k P_{\mathrm{N}_{2}}\right)} \\
& {[\% \mathrm{~N}]_{i}=\left\{-\alpha+\alpha^{2}+\frac{4 \alpha[\% \mathrm{~N}]+k^{2} P}{2}\right\}} \\
& \alpha=\frac{K m}{K c}+\frac{K m}{K g}+\frac{\rho R T}{100 M_{\mathrm{N}_{2}} K}
\end{aligned}
$$

Ban-ya et al. ${ }^{7)}$ have done an experiment of nitrogen absorption in molten steel under the $P_{\mathrm{N}_{2}}=1 \mathrm{~atm}$ and reported that the absorption rate was determined by the mass transfer rate of the metal phase. In the present study, a similar experiment has been done and the mass transfer rate constant was obtained from the experimental data as: $K m=0.014 \mathrm{~cm} / \mathrm{sec}$.

Taniguchi et $a l^{8)}$ have proposed a dimensionless equation to estimate the mass transfer rate constant in the gas phase. Taniguchi et al. have obtained the equation by using similar experimental apparatus to the present apparatus. Hence, $\mathrm{Kg}$ was obtained from this equation: $K g=0.44 \mathrm{~cm} / \mathrm{sec}$.

The chemical reaction rate constant was calculated from $K o v, K m$, and $K g$. Figure 12 shows the effect of oxygen and/or sulphur in melt on $K c$. The literature data $^{7,9,10)}$ is also shown in Fig. 12, the present data was

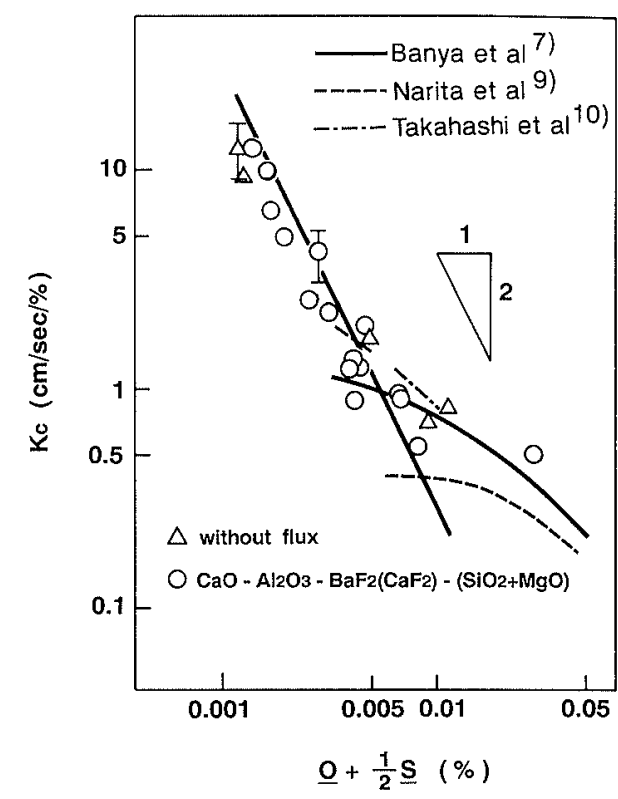

Fig. 12. Chemical reaction rate constant plotted against $\underline{\mathrm{O}}+\underline{\mathrm{S}} / 2$.

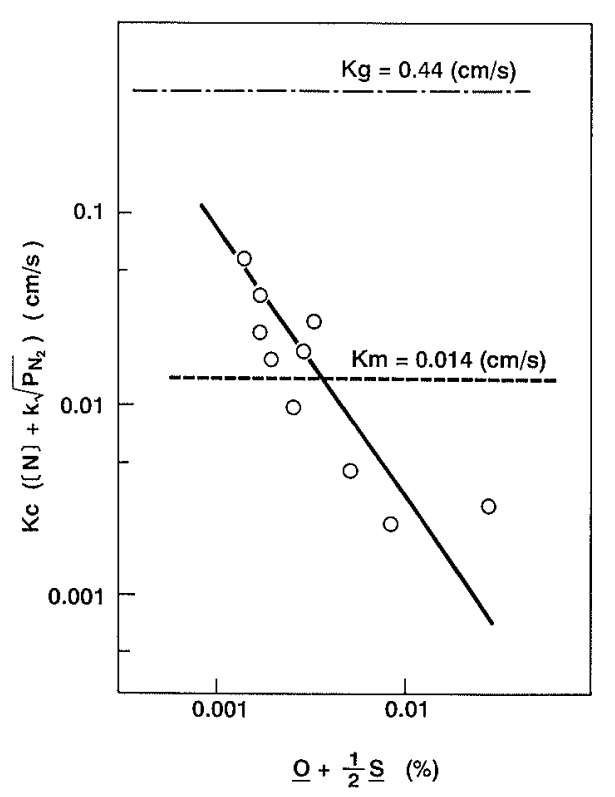

Fig. 13. Relationship between $\underline{\mathrm{O}}+\underline{\mathrm{S}} / 2$ and reaction rate constants.

$\mathrm{Kg}=$ mass transfer rate constant at gas phase, $K c=$ chemical reaction rate constant, and $K m=$ mass transfer rate constant at metal phase.

in agreement with the other data in the range. of $\underline{\mathrm{O}}+\underline{\mathrm{S}} / 2>0.01$. When the $\underline{\mathrm{O}}+\underline{\mathrm{S}} / 2<0.01, K c$ was increasing with decreasing $\underline{\mathrm{O}}+\underline{\mathrm{S}} / 2$ more rapidly than the tendency of the other range obtained from the literature data.

\subsection{Determination Step of the Reaction Rate}

The change in the chemical reaction rate constant with oxygen and/or sulphur in metal was compared with the mass transfer rate constant of the metal and gas phase, as shown in Fig. 13. When $\underline{\mathrm{O}}+\underline{\mathrm{S}} / 2$ is over 0.004 , the chemical reaction rate constant is smaller than the other rate constants. However, in the range of $\mathrm{O}+\mathrm{S} / 2<0.004$, $K c$ is larger than $K m$; mass transfer resistance in liquid 
could not be neglected in comparison with interfacial chemical reaction resistance. In this case, the overall nitrogen desorption rate was controlled by the transfer in the metal phase. Consequently, for application of the present process to a plant, it is necessary that the oxygen and sulphur in molten steel be reduced to as low as possible and the stirring of steel be strong.

\section{Conclusions}

Experiments of nitrogen desorption from molten steel with flux have been carried out. The measurement data have been analyzed based on the reaction rate. The results obtained are as follows.

(1) The flux system of $\mathrm{CaO}-\mathrm{Al}_{2} \mathrm{O}_{3}-\mathrm{CaF}_{2}-\mathrm{BaF}_{2}-$ $\mathrm{SiO}_{2}-\mathrm{MgO}$ is effective for nitrogen desorption from molten steel.

(2) The nitrogen distribution ratio between molten steel and slag is a maximum of 3 under the present experimental conditions.

(3) Nitrogen transfer from the molten steel to gas is promoted with decreasing surface activity elements, such as oxygen and sulphur, by using the present flux.

(4) The nitrogen desorption is controlled with the interfacial chemical reaction rate when $\mathrm{O}+\mathrm{S} / 2$ is below 0.004 . Above 0.004 , the nitrogen desorption is controlled with mass transfer in the metal phase.

\section{Nomenclature}

$A$ : interfacial area

$K$ : equilibrium constant, $\mathrm{N}_{2}=2 \mathrm{~N}$

$K o v$ : overall reaction rate constant

$L_{N}$ : nitrogen distribution between metal and slag

$M_{\mathrm{N}_{2}}$ : molecular mass of nitrogen
$[\% \mathrm{~N}]:$ nitrogen concentration in the molten steel at time $t$

$[\% \mathrm{~N}]_{i}$ : nitrogen concentration at the interface of molten steel

$[\% \mathrm{~N}]_{30}:$ nitrogen concentration in the molten steel at time $t=30 \mathrm{~min}$

$[\% \mathrm{~N}]_{0}$ : initial nitrogen concentration in the molten steel

$P_{\mathrm{N}_{2}}:$ nitrogen partial pressure

$\left(P_{\mathrm{N}_{2}}\right)_{i}$ : nitrogen partial pressure at the interface of the gas phase

Rs: $W_{M} / L_{N} W_{S}$

$V:$ volume of the molten steel

$W_{M}$ : weight of metal

$W_{S}$ : weight of slag

$\rho$ : density of the melt

\section{REFERENCES}

1) R. Inoue and H. Suito: Tetsu-to-Hagané, 73 (1987), S246.

2) E. Martinez and N. Sano: Tetsu-to-Hagané, 73 (1987), S245.

3) R. Yamanaka, K. Ogawa, S. Ito and S. Koyama: CAMP-ISIJ, 1 (1988), 255.

4) H. Iritani, T. Saito, R. Yamanaka, K. Ogawa and S. Koyama: CAMP-ISIJ, 12 (1989), 1126.

5) M. Sano, K. Kadoguchi and K. Mori: Trans. Iron Steel Inst. Jpn., 24 (1984), 825.

6) M. Sasagawa, Bahri Ozturk and R. J. Fruehan: Iron Steelmaker, 17 (1990), No. 12, 51

7) S. Ban-ya, T. Sinohara, H. Tozaki and H. Fuwa: Tetsu-to-Hagané, 60 (1974), 1443.

8) S. Taniguchi, A. Kikuti and S. Maeda: Tetsu-to-Hagané, 62 (1976), 191.

9) K. Narita, S. Koyama, T. Makino and M. Okamura: Tetsuto-Hagané, 57 (1971), 2207.

10) M. Takahashi, H. Matuda, M. Sano and K. Mori: Tetsu-toHagané, 72 (1986), 419 